\title{
ПАНДЕМИЯ И БАНКОВСКАЯ СФЕРА: НОВАЯ ЭКОНОМИЧЕСКАЯ РЕАЛЬНОСТЬ
}

\section{THE PANDEMIC AND THE BANKING SECTOR: A NEW ECONOMIC REALITY}

\section{A. Ushanov}

Summary. As a result of the complication of the situation in the nonfinancial sector of the economy due to COVID-19, the volume of economic activity of a number of major Russian companies in 2020 significantly decreased, which led to significant losses, an increase in overdue loans, etc. In the banking industry, which, although it retained important parameters of its work, there was a stagnation of the main financial indicators against the background of a decline in economic activity. In order to restore the economy as soon as possible against the background of the coronavirus pandemic, the Central Bank of the Russian Federation and the Government have adopted during 2020 a number of regulatory eases in the banking sector, including those aimed at supporting small and medium-sized businesses. However, the question of the degree of readiness of credit institutions to exit the regime of easing remains relevant. The article substantiates the need for a smooth exit of credit institutions from the regime of regulatory easing, analyzes the experience of accelerated digital transformation of banks against the background of the pandemic, and formulates priority tasks and directions for the development of the industry in the post-crisis period.

Keywords: coronavirus pandemic, regulatory easing, Bank of Russia support measures, loan portfolio quality, post-crisis period.

\author{
Уианов Александр Евгеньевич \\ К.э.н., дочент, Финансовый университет при \\ Правительстве РФ (г. Москва) \\ Ushanov_0656@mail.ru
}

Аннотация. В результате осложнения ситуации в нефинансовом секторе экономики из-за COVID-19 объемы хозяйственной деятельности ряда крупнейших российских компаний в 2020 году существенно снизились, что привело к значительным убыткам, росту просроченной задолженности по ссудам и др. В банковской отрасли, которая хотя и сохранила важные параметры своей работы, наблюдалась стагнация основных финансовых показателей на фоне снижения экономической активности. В целях скорейшего восстановления экономики на фоне коронавирусной пандемии ЦБ РФ и Правительство приняли в течение 2020 г. ряд регуляторных послаблений в банковском секторе, в том числе направленных на поддержку малого и среднего бизнеса. Актуальным, однако, остается вопрос о степени готовности кредитных организаций к выходу из режима послаблений. В статье обоснована необходимость плавного выхода кредитных организаций из режима регуляторных послаблений, проанализирован опыт ускоренной цифровой трансформации банков на фоне пандемии, сформулированы приоритетные задачи и направления развития отрасли в постковидный период.

Ключевые слова: пандемия коронавируса, регуляторные послабления, меры поддержки Банка России, качество кредитного портфеля, постковидный период.

Помимо этого, ситуация усугубилась серьезным оттоком из банков (из-за низких процентных ставок) денежных средств вкладчиков - на 1 ноября 2020 г. он составил 1,5 трлн. руб.

Это проявилось, в частности, в стагнации основных финансовых показателей сектора к IV кварталу 2020 г. на фоне снижения экономической активности, связанного с увеличением темпов распространения пандемии и вводимыми ограничениями на бизнес [2]; наблюдались временное сжатие кредитной активности и рост отчислений в резервы.

\section{Регуляторные послабления}

В целях поддержки скорейшего восстановления экономики на фоне коронавирусной пандемии ЦБ РФ и Правительство приняли в течение 2020 г. ряд регуляторных послаблений в банковском секторе (см. рис. 1). 
Меры Банка России по поддержке экономики на фоне пандемии COVID-19

Право принимать решение о неухудшении оценки ФП ряда заемщиков

Право не ухудшать оценку ФП и (или) КОД по ссудам I и II категорий качества, предоставленным лизинговым компаниям

Право не ухудшать КОД или ФП заемщика по реструктури-рованным ссудам, предусматриваю-щим изменение валюты кредита

Не считать нарушением несоблюдение банками СЗКО норматива Н26 (Н27) при определенных условиях

Повышение доступности среднесрочного и долгосрочного фондирования (аукционы РЕПО, расшир. ломб. списка)

Урегулирование проблемных кредитов СЗКО через обмен долга на их акции

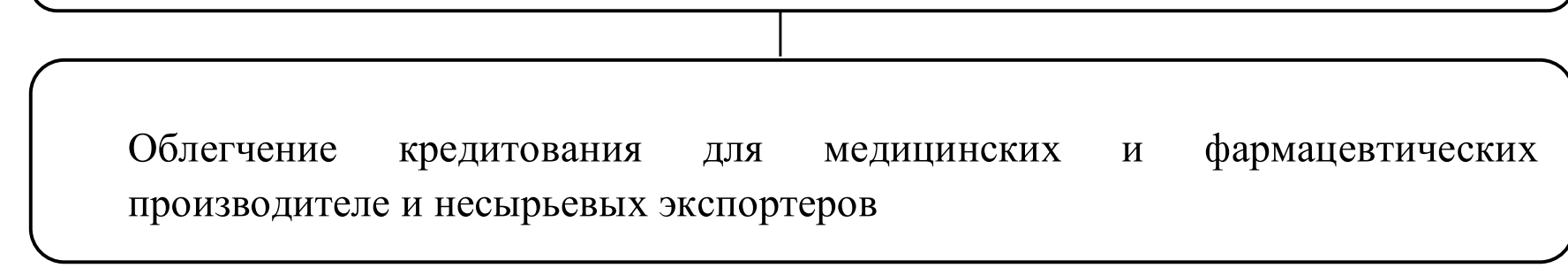

Рис. 1. Регуляторные послабления Банка России кредитным организациям в условиях пандемии COVID-19

ФП - финансовое положение, КОД - качество обслуживания долга, СЗКО - системно-значимые кредитные организации 
Право банков сформировать резервы по реструктуриров. в связи с пандемией кредитам до 1.04. 2021 г.

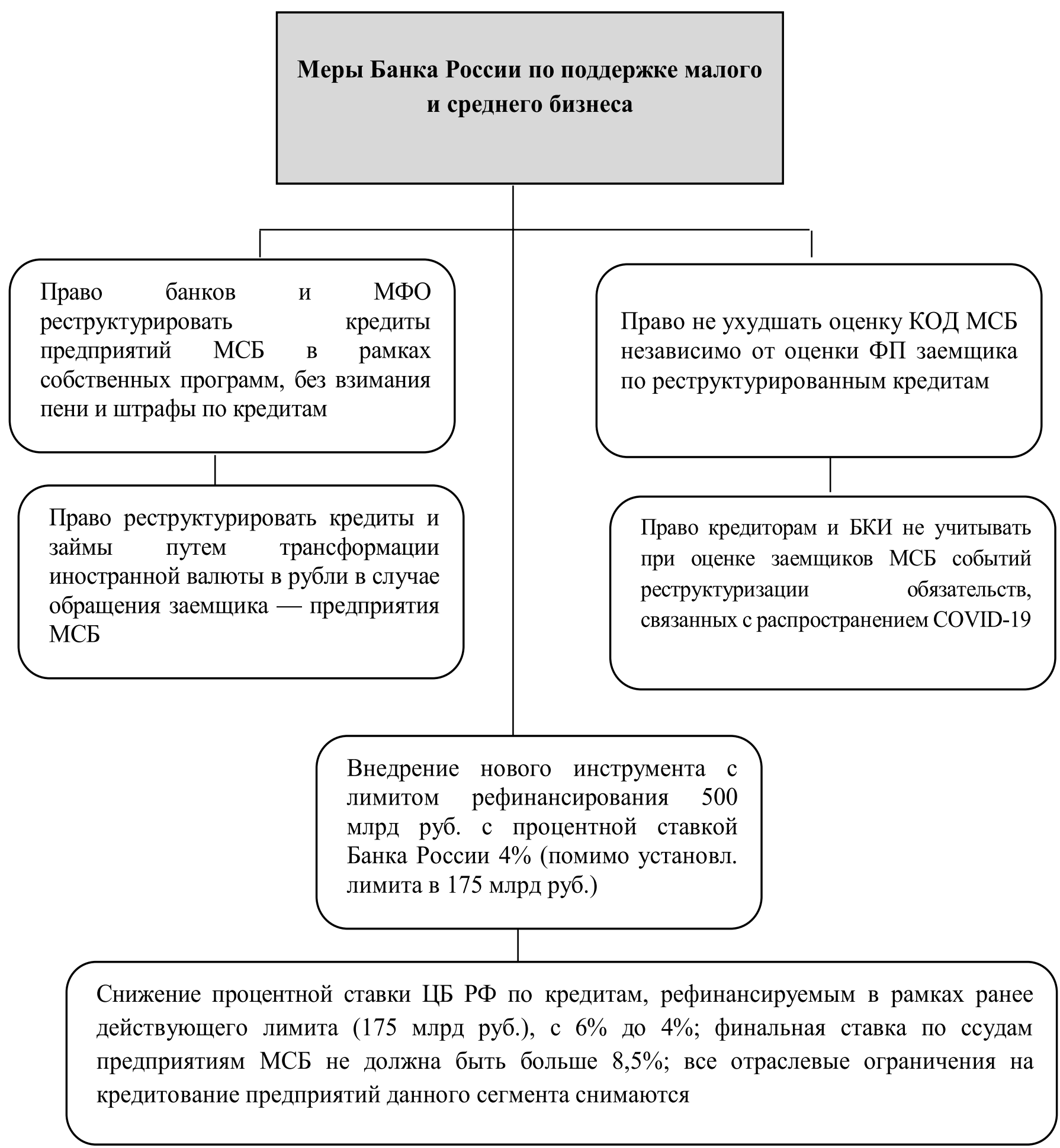

Рис. 2. Меры ЦБ РФ по поддержке предприятий малого и среднего бизнеса МФО - микрофинансовые организации, МСБ - малый и средний бизнес, БКИ - Бюро кредитных историй 
Сегмент малого и среднего предпринимательства сектор экономики, больше других пострадавший из-за пандемии, а также связанных с ней ограничительных мер. В этой связи, с целью поддержки способности предприятий и организаций сектора обслуживать банковские ссуды, мегарегулятор предпринял на период 2020 года следующие шаги (рис. 2).

Несмотря на указанные выше негативные явления, важные параметры работы банковской отрасли даже в период пандемии сохранили, а то и увеличили свои значения. Так, корпоративный кредитный портфель в июне 2020 г. вырос на 204 млрд. руб. (+0,5\%), розничный - на 179 млрд. руб. (+1\%), в то время как в мае динамика обоих портфелей была практически нулевой. В целом по итогам года рост корпоративных кредитов составил 10\%, что почти в два раза выше, чем в 2019 г. Однако нельзя забывать, что в части корпоративного кредитования рост был почти целиком обеспечен кредитами финансовым компаниям (в том числе в форме сделок обратного РЕПО), тогда как объем кредитования предприятий реального сектора практически не изменился; его сохранение во многом обеспечено государственными программами поддержки корпоративных заемщиков, включая предприятия малого и среднего бизнеса, рост кредитования которого в 2020 г. составил $20 \%$.

Что касается роста розничного кредитования, то он в большей степени обусловлен ипотекой, в том числе в рамках государственной программы (под 6,5\% годовых). Программа была эффективным инструментом в период острой фазы кризиса и сразу после выхода из него, но по известным причинам будет постепенно сворачиваться [3].

\section{Риски потерь}

Ухудшение состояния кредитного портфеля как следствие кризиса некоторых отраслей экономики, предприятия которых являются заемщиками, эксперты считают основным риском кредитных организаций. По оценке главы ВТБ А. Костина, например, потери банковского сектора могут составить около 2,5 трлн. руб. [4].

Ситуация может осложниться тем, что, как отмечают аналитики агентства «Эксперт РА, основная часть средств, полученных реальным сектором в рамках господдержки, пошла не на инвестиции в развитие, а на затыкание дыр, ограничение катастрофических потерь для фирм. Существенная часть задолженности, которая не будет списана или погашена государством, окажется в категории «плохих долгов».

Выход должен быть постепенным
Тем не менее, главное, что удалось сделать,- это не допустить реализации негативного сценария развития событий и адаптировать работу банковского сектора к условиям коронавирусной пандемии. Разносторонние меры господдержки создали условия для реструктуризации кредитов, позволили определенной части кредитных заемщиков восстановить свое финансовое состояние. Однако регуляторные послабления - временная мера. Как подчеркнул в своем интервью агентству «Интерфакс» первый зампред ЦБ РФ Д.Тулин, «...игра в регуляторные послабления, если они не временные, а де-факто постоянные, это такое же лукавство, жульничество, как с настройкой весов, самообман» [5].

Вместе с тем, выход из режима регуляторных послаблений не должен быть быстрым: кредитные организации в условиях неизбежного восстановления резервов должны иметь возможность адаптироваться и не сокращать кредитование реального сектора экономики. Аккуратность, плавность и постепенность - таковы принципы отмены регуляторных послаблений, отмечаемые В качестве приоритетных главой ЦБ РФ Э. Набиуллиной [6], председателем комитета Госдумы по финансовому рынку А. Аксаковым [7] и другими.

Немаловажным здесь представляется вопрос, готовы ли отечественные банки к отмене послаблений. Очевидно, что только восстановление нормального функционирования кредитных организаций будет способствовать возврату к доковидному уровню деятельности предприятий и организаций, а это, в свою очередь, окажет поддержку населению, доходы различных групп которого значительно сократились. Что касается восстановительного периода, который необходимо будет пройти как экономике в целом, так и банковскому сектору, то его длительность пока трудно оценить. Однако очевидно, что в условиях снижения банковской маржи, неустойчивости кредитные организации будут вынуждены ускоренными темпами искать пути трансформации модели (моделей) ведения бизнеса, сокращения неоперационных расходов, сосредоточения внимания к выявлению потенциально проблемных активов, чтобы не допустить снижения качества кредитного портфеля.

\section{$\triangle$ Айствия \\ в посткови ный перио $\Delta$}

Известно, что европейские банки действуют в экономических условиях, отличных от российских. Вместе с тем проблемы, вызванные эпидемией COVID-19, схожи: падение ставок, рост проблемных активов, снижение доходов в ближайшее время. Поэтому советы международной консалтинговой компании McKinsey \& 
Company, которые она дает банкам в их работе в постковидный период, хотя и не содержат каких-либо принципиально новых моментов, интересны и для российских банков. К ним относятся, в частности, рекомендации [8]:

- создавать новые продукты и предложения для клиентов, постоянно анализируя рынок;

- переходить на цифровое обслуживание, перепрофилируя банковские отделения, которые стали менее посещаемыми;

- пересмотреть свои расходы, сократив их на 20$30 \%$, компенсируя тем самым возрастание рисков и падение доходов;

- расширять сотрудничество с IT-отделами и использование искусственного интеллекта;

- уделять больше внимания управлению рисками в целях раннего обнаружения проблемных актиBOB;

- искать бизнес-партнеров, в т.ч. для сделок М\&A; они помогут банкам выжить в условиях снижения доходов.

В отечественной экономической литературе уже появились публикации [9 и др.], где поднимаются вопросы, на которые как на государственном, так и на локальном уровне в приоритетном порядке следует акцентировать внимание в постковидный период. Среди них:

- обеспечение гибкого регулирования со стороны Банка России в рамках постепенного выхода из режима послаблений, в том числе путем создания и постоянной корректировки дорожной карты, в том числе в части восстановления резервов;

- обеспечение заинтересованности кредитных организаций в поиске долгосрочных источников финансирования, развитие проектного финансирования;

- повышение эффективности моделей ведения бизнеса банков с использованием современных технологических решений;

- обеспечение эффективного управления операционными рисками, а также качеством кредитного портфеля, в т.ч. за счет его проактивной диагностики;

- корректировка законодательных основ досудебного и судебного урегулирования задолженности, создание специального фонда реструктуризации «плохих» активов;

- внесение соответствующих изменений в Федеральный закон от 03.04.2020 N106-Ф3;

- консолидация плохих долгов, например, на базе банка непрофильных активов «Траст»;

- постановка вопроса о подготовке программы докапитализации (рекапитализации) банковского сектора и др.

\section{Ускорение digital-трансформашии}

Одним из феноменов, вызванных коронавирусной инфекцией, стало то, что оперативная реакция коммерческих банков на ее вызовы была отмечена уже в ходе самой пандемии. Выросла скорость принятия решений, быстрее разрабатываются новые сервисы и продукты; если прежде эта работа отнимала несколько месяцев, то теперь - несколько недель. Пандемия становится драйвером для ускоренной digital-трансформации банковского бизнеса [10][11]. Проиллюстрируем это на примере нескольких российских топ-банков.

«Уралсиб»:

- запуск в мае 2020 г. карты «Прибыль», которую банк разработал на основании пожеланий клиентов. Она объединила в себе наиболее востребованные у целевой аудитории возможности - кэшбэк за покупки и достаточно высокий процент на остаток, что позволяло рассматривать ее как альтернативу традиционным вкладам;

- запуск сервиса электронной регистрации ипотечных сделок, позволяющий регистрировать сделки электронно по всей стране, причем бесплатно для своих клиентов и партнеров.

«ВТБ»:

- создание полностью дистанционного формата покупки автомобиля;

- обеспечение возможности для потенциального клиента банка стать им дистанционно при помощи биометрии, оперативную проконсультироваться в чате и мессенджере Viber, получить цифровую банковскую карту.

Стратегическая задача банка «ВТБ» - перевод 100\% продуктов для частных клиентов в онлайн-каналы к 2022 году.

Банк «Санкт-Петербург»:

- реализация полностью цифровой карты, выпуск которой можно осуществить в мобильном или интернет - банке, а затем привязать ее к Apple или Google- кошельку и использовать как обычную карту.

«Сбербанк»:

- активное развитие мобильного приложения Сбербанк Бизнес Онлайн на платформах iOS и Android - добавление в нем маркетплейс сервисов для развития и ведения бизнеса, возможность оплаты по QR-коду, подписание платежей через Touch ID и Face ID, интеграция сервиса «Проверки контрагентов» в процесс создания платежа и т.п. 
Российская банковская отрасль в ближайшем будущем будет продолжать меняться по самым разным направлениям: доля удаленной работы и «безофисных» форматов обслуживания будет расти, а бизнес-процессы - трансформироваться; онлайн и доставка станут привычным способом взаимодействия с клиентами.

Продолжится поиск оптимального баланса между онлайн- и офлайн-форматами с точки зрения их наиболее эффективной комбинации: простые и стандартные сделки и операции по максимуму уйдут в онлайн, а сложные сделки (инвестиции, структурирование корпоративных ссуд, частично ипотека и др.) будут совершаться в офисах. Предстоит активное развитие онлайн - каналов, маркетплейсов, экосистем.

\section{Выво $\Delta$}

Регуляторные послабления, введенные Банком России в 2020 году в отношении кредитных организаций на фоне пандемии коронавирусной инфекции, являются исключительно временной мерой. Как их затягивание, так и резкая отмена негативно скажутся на финансовом состоянии банков, вынужденных восстанавливать свои резервы, снизят возможности развивать кредитование реального сектора экономики, в конечном счете негативно повлияют на процесс восстановления реальных доходов населения. Практическое значение полученных результатов состоит в формулировании рекомендаций по развитию банковской отрасли в постковидный период.

\section{ЛИТЕРАТУРА}

1. «Убыток «Аэрофлота» по МСФ0 в 1-м полугодии составил 58,27 млрд. руб.». [Электронный ресурс]. URL: http://www.finmarket.ru/news/5303834.31.08.2020.

2. «В октябре банковский сектор показал стагнацию основных финансовых показателей». [Электронный ресуpc]. URL: https://arb.ru/banks/analitycs/V_ oktyabre_bankovskiy_sektor_pokazal_stagnatsiy_osnovnykh_finansovykh_pokazatel_10438102/?sour.08.12.2020.

3. Пресс-конференция Э. Набиуллиной. 12.02.2021. [Электронный ресурc]. URL: https://www.interfax.ru/business/750685

4. «Костин оценил потери банков от коронавируса в сумму до 2,5 трлн. рублей». Интервью А. Костина PБК. [Электронный pecypc]. URL: https://www.interfax. ru/business/704998. 20.04.2020.

5. Первый зампред ЦБ РФ: постоянные регуляторные послабления — это жульничество с подкруткой весов». [Электронный pecypc]. URL: https://www. interfax.ru/interview/741376. 15.12.2020.

6. Выступление Э. Набиуллиной на встрече в Ассоциации банков России. [Электронный ресурc]. URL: https://cbr.ru/press/event/?id=9598. 18.02.2021.

7. «Банки будут постепенно выходить из регуляторных послаблений в течение года». [Электронный ресурс]. URL: https://ib-bank.ru/bisjournal/news/14124. 5.09.2020.

8. «Что делать банкам после пандемии COVID-19: советы McKinsey». [Электронный ресурс]. URL: https://frankrg.com/16976. Аналитический отчет компании Franc RG. 20.05.2020.

9. Азаров С.В. Анализ банковской системы в условиях пандемии / Современная наука: актуальные проблемы теории и практики, серия «Экономика и право», N1 (январь), 2021, с. 5-9.

10. Соколинская Н.Э., Зиновьева Е.А. Банковский сектор до и после пандемии / Финансовые рынки и банки, 6, 2020, с. 84-86.

11. Мартыненко Н.Н Риски ускоренного внедрения дистанционного банковского обслуживания населения в условиях пандемии: причины, следствия, направления сдерживания / Финансовые рынки и банки, N6, 2020, с. 75-80.

() Ушанов Александр Евгеньевич (Ushanov_0656@mail.ru ).

Журнал «Современная наука: актуальные проблемы теории и практики» 